\title{
Mimicking Neural Stem Cell Niche by Biocompatible Substrates
}

\author{
Citlalli Regalado-Santiago, Enrique Juárez-Aguilar, \\ Juan David Olivares-Hernández, and Elisa Tamariz \\ Instituto de Ciencias de la Salud, Universidad Veracruzana, Avenida Luis Castelazo Ayala, s/n, 91190 Xalapa, VER, Mexico \\ Correspondence should be addressed to Elisa Tamariz; etamariz@uv.mx
}

Received 1 July 2015; Revised 19 October 2015; Accepted 23 November 2015

Academic Editor: Ashok K. Shetty

Copyright (c) 2016 Citlalli Regalado-Santiago et al. This is an open access article distributed under the Creative Commons Attribution License, which permits unrestricted use, distribution, and reproduction in any medium, provided the original work is properly cited.

\begin{abstract}
Neural stem cells (NSCs) participate in the maintenance, repair, and regeneration of the central nervous system. During development, the primary NSCs are distributed along the ventricular zone of the neural tube, while, in adults, NSCs are mainly restricted to the subependymal layer of the subventricular zone of the lateral ventricles and the subgranular zone of the dentate gyrus in the hippocampus. The circumscribed areas where the NSCs are located contain the secreted proteins and extracellular matrix components that conform their niche. The interplay among the niche elements and NSCs determines the balance between stemness and differentiation, quiescence, and proliferation. The understanding of niche characteristics and how they regulate NSCs activity is critical to building in vitro models that include the relevant components of the in vivo niche and to developing neuroregenerative approaches that consider the extracellular environment of NSCs. This review aims to examine both the current knowledge on neurogenic niche and how it is being used to develop biocompatible substrates for the in vitro and in vivo mimicking of extracellular NSCs conditions.
\end{abstract}

\section{Introduction}

Stem cells are characterized by their extensive potential for proliferation and differentiation, as well as their major role in homeostasis and tissue regeneration. Although stem cells are a promising source for cell replacement therapies and cell regeneration after injury or disease, their use is still limited because there are several factors that must be taken into account, such as survival, tissue integration, specific differentiation, and functionality. In order for them to be considered within regenerative medicine, it is imperative to understand their in vivo biology and microenvironment, or niche. In recent years, the use of in vitro models that simulate various components of the niche has helped the understanding of the role of the various factors that compose it and even the design of artificial models that recapitulate microenvironment conditions $[1,2]$. In that sense, biocompatible substrates are an alternative for the incorporation of different physical and chemical properties that can modulate the biology of stem cells and improve their manipulation [3]. This paper will review some of the main extrinsic characteristics of the neurogenic niche and how current knowledge about it is being used to design biocompatible substrates that mimic the microenvironment of neural stem cells in order to regulate their biology, as well as the impact this may have on the future of tissue regeneration therapies.

\section{Embryonic and Adult Neural Stem Cells}

Neural stem cells (NSCs) originate the main cell types in the central nervous system (CNS) during development and adulthood. These cells are able to self-renew through cell division and have the capacity to generate specialized cell types. NSCs generate other NSCs, which maintain their differentiation potential and their proliferation or self-renewal capacity, and/or originate transit-amplifying cells or neural progenitor cells (NPCs), which display decreased proliferative potential and limited capacity to differentiate into neurons, astrocytes, and oligodendrocytes. From early embryonic development up to early postnatal stages, neurons are the main cell types generated, while late embryogenesis is characterized by the production of both astrocytes and oligodendrocytes, which continues during postnatal stages and throughout adult life 


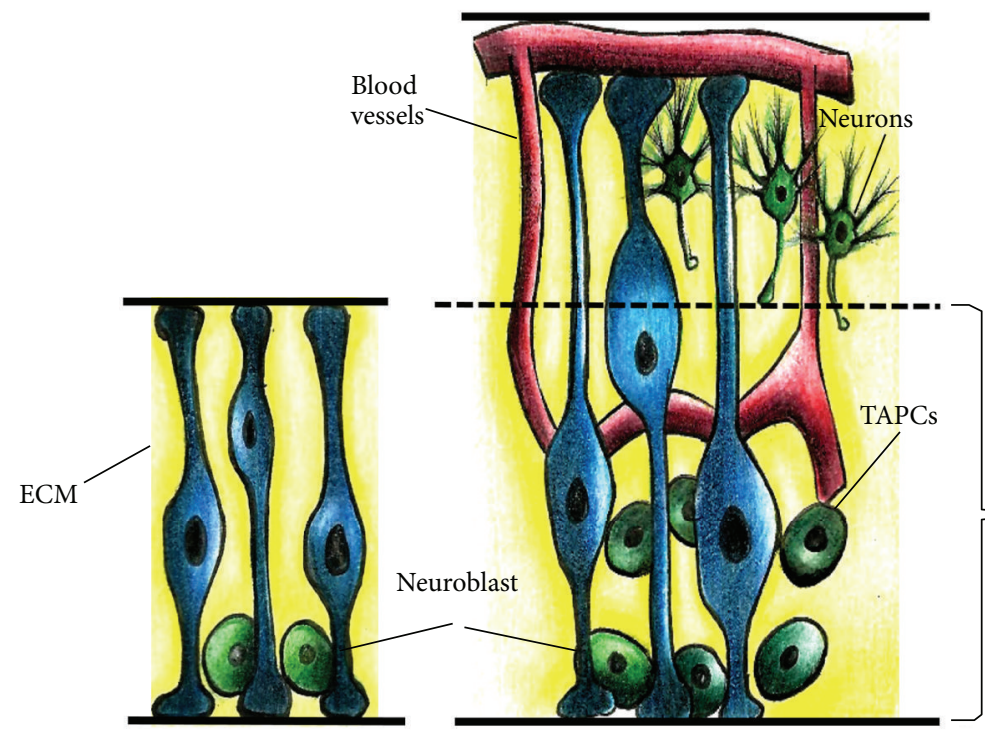

(a)

(b)

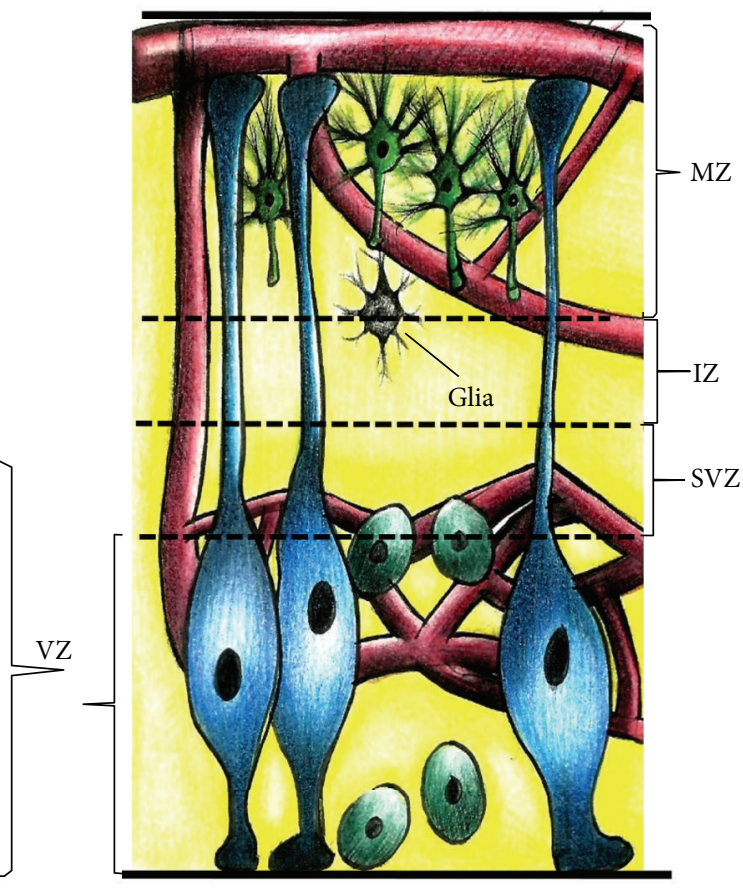

(c)

Figure 1: Neural stem cell niche in the early stages of CNS development. (a) During early embryogenesis, neuroepithelial cells transform into radial glial cells (RGCs) with cell process elongating toward the pial surface of the neural tube. RGCs divide asymmetrically to form neuroblasts. (b) Neuroblast division generates progenitors known as "transit-amplifying progenitor cells" (TAPCs), which divide rapidly and generate the first local neural niche or ventricular zone (VZ); at this stage the first blood vessels invade the neural tube from the dorsal region toward the VZ zone and extend their branches tangentially to the pial surface. (c) In the forebrain, TAPC proliferation produces a second germinal zone, the subventricular zone (SVZ). In this zone, postmitotic neuroblasts and glioblasts migrate toward the dorsal intermedia and marginal zones and produce neurons and glial cells. CNS, central nervous system; ECM, extracellular matrix; IZ, intermediate zone; MZ, marginal zone.

[4]. The process of generating functional neurons or glial cells from precursors is defined as neurogenesis and was thought to occur only during the embryonic and perinatal stages in mammals. Currently, it is widely accepted that neurogenesis takes place in the adult brain and that the neural stem cells of this organ are descendants of their embryonic counterparts.

A number of significant questions remain regarding the biology of embryonic and adult neural stem cells. How is the fate of NSCs determined? What determines whether NSCs remain in their stem stage or differentiate into one of the three mature phenotypes? Over the last few years, it has become clear that NSCs are sensitive to multiple signals during development, including extracellular matrix proteins, growth and transcription factors, or even the interaction with different cell types in their proximity $[5,6]$. Although apparently of the same nature as their embryonic counterparts, adult NSCs show different responses to the same regulators. At the same time, these cells are mostly quiescent in the adult brain with a low neuron production rate in contrast to the high proliferative rate of the embryonic NSCs. Additionally, neuronal maturation is accomplished at a slower rate in the adult brain than in the embryo. Although the reason for these differences is not clear, it has been reported that the acceleration of the maturation rate sometimes leads to the aberrant integration of newborn neurons in the adult hippocampus [7]. It has been suggested that, besides intrinsic differences, changes in the microenvironment surrounding neural stem cells during both development and adult life modulate their biological response [7].

During early embryogenesis, NSCs are not specifically localized and are instead organized as a single layer of proliferating neuroepithelial cells in the neural tube. Early in the neural tube formation, cells at the junction of the tube form the neural crest cells, which migrate out of the tube to form the neurons and glia of the peripheral nervous system as well as other non-nervous system cells, such as melanocytes, chondrocytes, and craniofacial osteocytes [86]. Neuroepithelial cells in the neural tube divide symmetrically, generating two identical daughter cells. Once this population has increased, they switch to a new form of asymmetrical division, producing two distinct daughter cells, the typical self-renewing stem cell and the neuroblast, with the former transforming into radial glial cells (RGCs) that exhibit neuroepithelial and glial proteins, extending a long cell process towards the outer neural tube region or pial surface (Figure 1(a)). As brain development proceeds, the proliferation of RGCs and neuroblasts generate several layers that surround the interior face of the neural tube, leading 


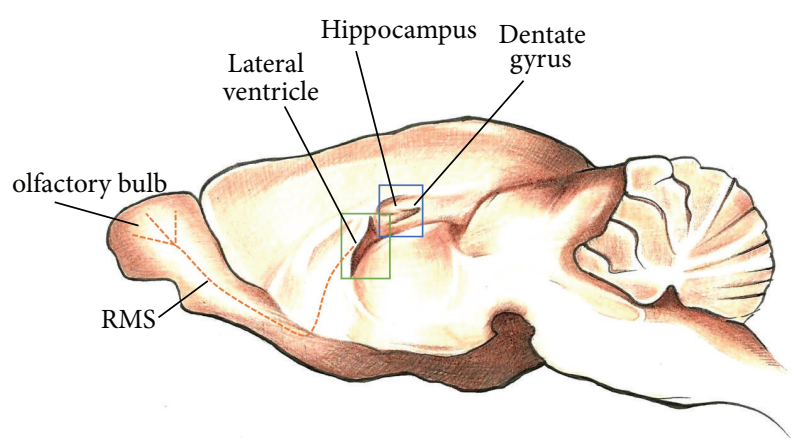

(a)

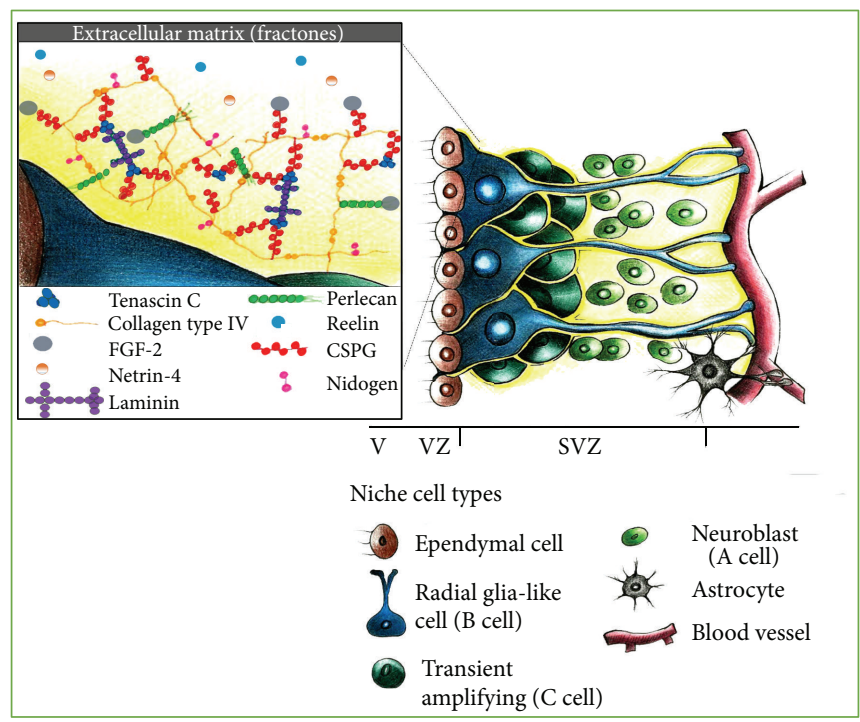

(b)

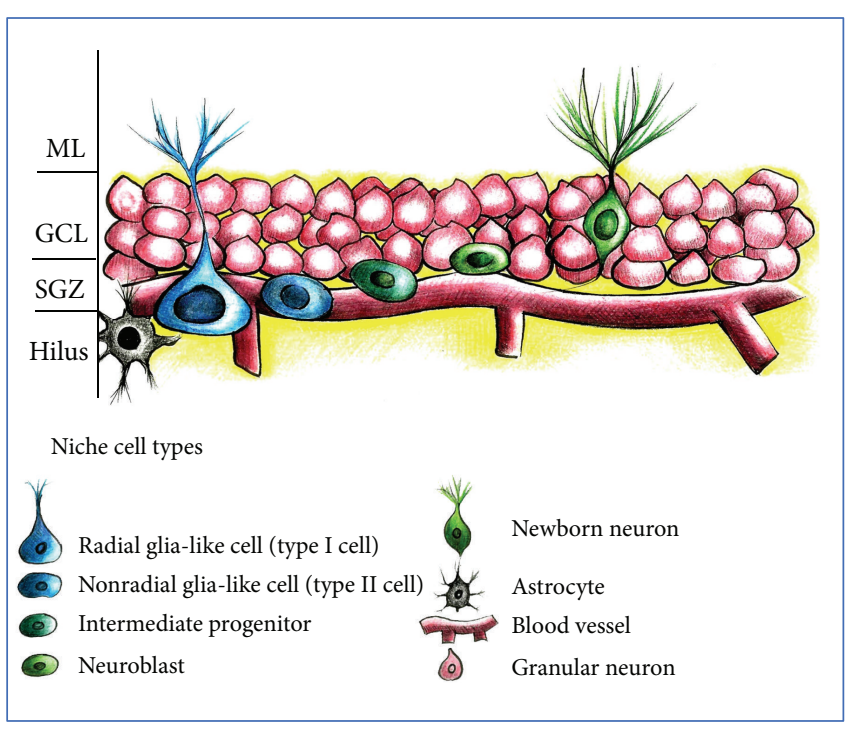

(c)

FIGURE 2: Neural stem cell niche in the adult dentate gyrus and subventricular zone. (a) Sagittal section view of an adult rodent brain showing the two main restricted regions where active adult neurogenesis is present, the dentate gyrus in the hippocampal formation and the lateral ventricle, from which type A cells migrate to form the rostral migratory stream (RMS) toward the olfactory bulb. (b) Neural stem cell niche in the subventricular zone (SVZ). Three types of progenitor cells are found close to the ependymal cell layer in the SVZ: a population of radial glia-like cells (type B cells) have the potential to serve as adult neural stem cells (NSCs) and generate transit-amplifying nonradial NSCs (type C cells), which later give rise to neuroblasts (type A cells). The SVZ includes several ECM components (yellow), called fractones (inset), which make contact with all the cell types, including the blood vessels and astrocytes in this region. (c) In the adult subgranular zone (SGZ), a population of radial glia-like cells (type 1 cells), along with nonradial glia-like cells (type 2 cells), generate neuroblasts. These neuroblasts then migrate into the granule cell layer and mature into neurons. CSPG, chondroitin sulfate proteoglycan; FGF2, fibroblast growth factor 2; GCL, granular cell layer; ML, molecular layer.

to the first local neural niche called the ventricular zone (VZ) (Figure 1(b)). The neuroblasts and glioblasts with high proliferating capacity also termed intermediate progenitor or "transit-amplifying progenitor cells" (TAPCs) generate postmitotic cells that finally differentiate into neurons and glial cells. In the forebrain region, the TAPCs accumulate above the VZ, forming a second germinal zone, the subventricular zone (SVZ) (Figure 1(c)). All these populations are also in close contact with cells of nonneural origin, such as endothelial cells from the blood vessels, microglia, and pericytes [5, 87]. Interactions among all these cells, together with the temporal and spatial synthesis of soluble and insoluble factors during CNS development, result in the establishment of the intricate neural network that will support the function of this system in postnatal life [88].

After the embryonic phase of CNS development, some NSCs populations remain in specific neurogenic niches throughout the lifespan of the brain. Two specific and welldescribed neurogenic regions remain in the adult brain after the embryonic phase, the subgranular zone (SGZ) in the dentate gyrus (DG) of the hippocampus and the subventricular zone (SVZ) of the lateral ventricles (Figure 2). While the neurogenesis in these neurogenic sites results in the generation of new neurons in the brain, there are differences in the type of neurons generated. Neurogenesis produces dentate granule cells in the SGZ of the DG of 
the hippocampus, while neurogenesis in the SVZ of the lateral ventricles produces interneurons that migrate to the olfactory bulb (Figure 2(a)). The production of mature neurons in these neurogenic sites comprises several steps that resemble embryonic neurogenesis.

Neurogenesis of the adult SVZ begins with the activation of quiescent radial glia-like cells (termed type B cells) in the subventricular zone in the lateral ventricle and continues with the proliferation of transit-amplifying progenitor cells (type $C$ cells), resulting in an increase in the neuroblast population (type A cells) or glia (oligodendrocytes or astrocytes) (Figures 2(a) and 2(b)). In the rostral migratory stream (RMS), type A cells form a chain and migrate toward the olfactory bulb through a tube formed by astrocytes. Upon reaching the olfactory bulb, immature neurons leave the RMS and migrate radially toward the glomeruli, where they differentiate into different subtypes of interneurons that, finally, are synaptically integrated [89] (Figure 2(a)). Type B cells are in close contact with the ependymal cell layer through a thin apical process and with SVZ vasculature through a basal process. This structural polarity allows type B cells to be in simultaneous contact with both vascular and cerebrospinal fluid (CSF) compartments [7] (Figure 2(b)). In other cases, hippocampal neurogenesis in the DG begins, as in SVZ neurogenesis, with the proliferation of radial (type I cell) and nonradial (type II cell) precursors that give rise to intermediate progenitors, which in turn generate neuroblasts (Figures 2(a) and 2(c)). Unlike in SVZ neurogenesis, immature neurons are not required to migrate long distances in order to initiate the differentiation process. The new immature neurons move into the inner granule cell layer and differentiate into dentate granule cells in the hippocampus. Within days, newborn neurons extend dendrites toward the molecular layer and project axons through the hilus toward the CA3. New neurons follow a stereotypic process for synaptic integration into the existing circuitry [89].

Besides the classic neurogenic sites, there is evidence indicating the presence of other neurogenic sites in the brain that are more evident after injury or growth factor stimulation, such as the walls of the third and fourth ventricle and the circumventricular organs. All of these sites are close to blood vessels [90], although their detailed characterization and contribution after brain damage are still the subject of intense study.

\section{Neural Stem Cell Niche: Characteristics and Relevance}

The anatomical distribution of many stem cells has been a troublesome task due to the low accessibility and restricted areas where they are located. Currently it is accepted that the tissue areas where stem cells lie are specialized microenvironments with specific cellular, chemical, and physical properties [2].

As mentioned above, embryonic and adult NSCs are influenced by their microenvironment. The microenvironment concept is related to the presence of extracellular matrix proteins and soluble factors such as hormones and growth factors in the extracellular space (some of which are summarized in Table 1). However, these are not the only factors that can influence the biology of the NSCs. It has been evident that interactions with neighboring cells are also a relevant modulator of the biology of these cells in both the embryo and the adult. Endothelial cells, astrocytes, ependymal cells, microglia, mature neurons, and the progeny of adult neural stem cells are additional regulators of the fate of the NSCs. All of these elements in the cellular microenvironment constitute the neurogenic niche that anatomically houses stem cells and functionally controls their development in vivo [90]. As excellent and extensive reviews have been published on the neurogenic niche $[5,88,91-94]$, this section is only a brief summary, which includes examples of the different factors that could be taken into account in biocompatible substrate design.

The neurogenic niche determines whether a NSCs divides or remains as a quiescent cell as well as whether it survives, dies, proliferates, migrates, or differentiates into different neural cells $[6,95,96]$. During the development of the CNS, the VZ of the neural tube is mainly comprised by the proliferative cells of the neuroepithelium. Segmentation and regionalization of the neural tube modify and restrict the neurogenic areas during the developmental stages, leading to a niche that is spatially, chemically, and cellularly variable [97, 98]. During the changes, stem cells and progenitors in the VZ and SVZ remain in contact with specific extracellular components such as growth factors, ECM components, and cells that modulate their division and differentiation. During the development of the neocortex, for example, neuroepithelial cells proliferate to form several layers of cells surrounding the lumen of the neural tube. As mentioned above, the inner cells transform into RGC, whose asymmetric divisions generate self-renewing cells that stay in the $\mathrm{VZ}$, and progenitor cells that migrate to the SVZ. After several divisions, the progenitors go from the SVZ to their destination through radial and tangential migration and differentiate into neurons and glia $[5,96,99]$. Several transcription factors, proteins related to cell polarity, such as cadherins and nectin, as well as signaling components are all activated in a complex that promotes the dissolution of cell adherens junctions and the reorganization of the actin cytoskeleton to favor progenitor migration [100].

The vascularization of the neural tube is closely related to neural development. The timing of angiogenesis is similar to the neurogenesis. The RGCs secrete several growth factors, such as vascular endothelial growth factor (VEGF), transforming growth factor beta two (TGF $\beta-2)$, and fibroblast growth factor two (FGF2), which, in turn, induce vasculature development, while the growth factors secreted by endothelial cells, such as VEGF and Jagged-1 (a Notch ligand), influence neurogenesis [5]. Furthermore, nonneural cells are also involved in establishing and supporting the neurogenic niche [5]. For example, it has been shown that, during brain development, pericyte cells synthesize the sonic hedgehog (Shh) protein, which plays an important role in the proliferation of the neuroepithelial cells that conform the VZ [101].

In the postnatal and adult brain, the main neurogenic niches in the SVZ and the DG play a role in maintaining the balance between stemness and NSCs differentiation. 


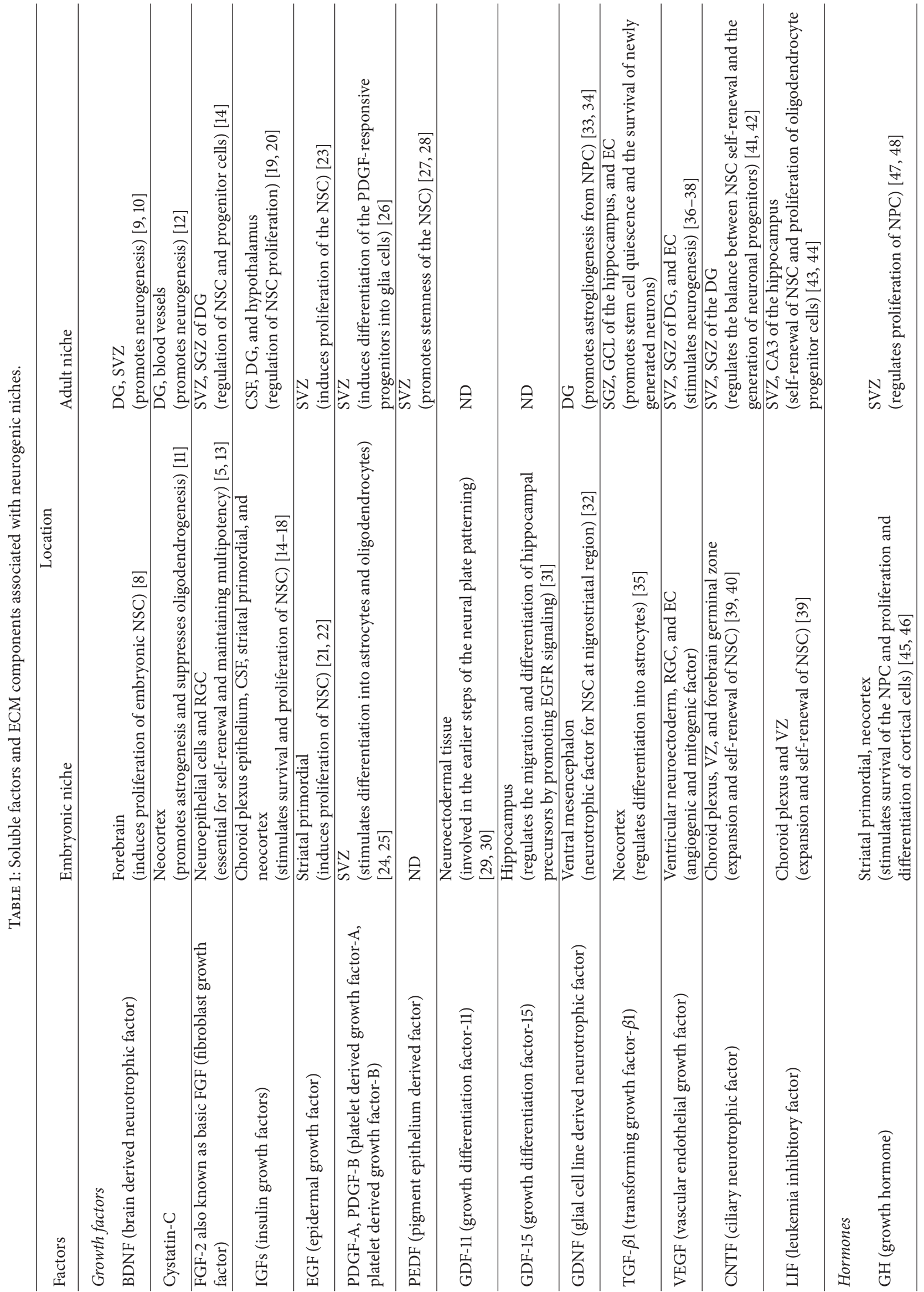




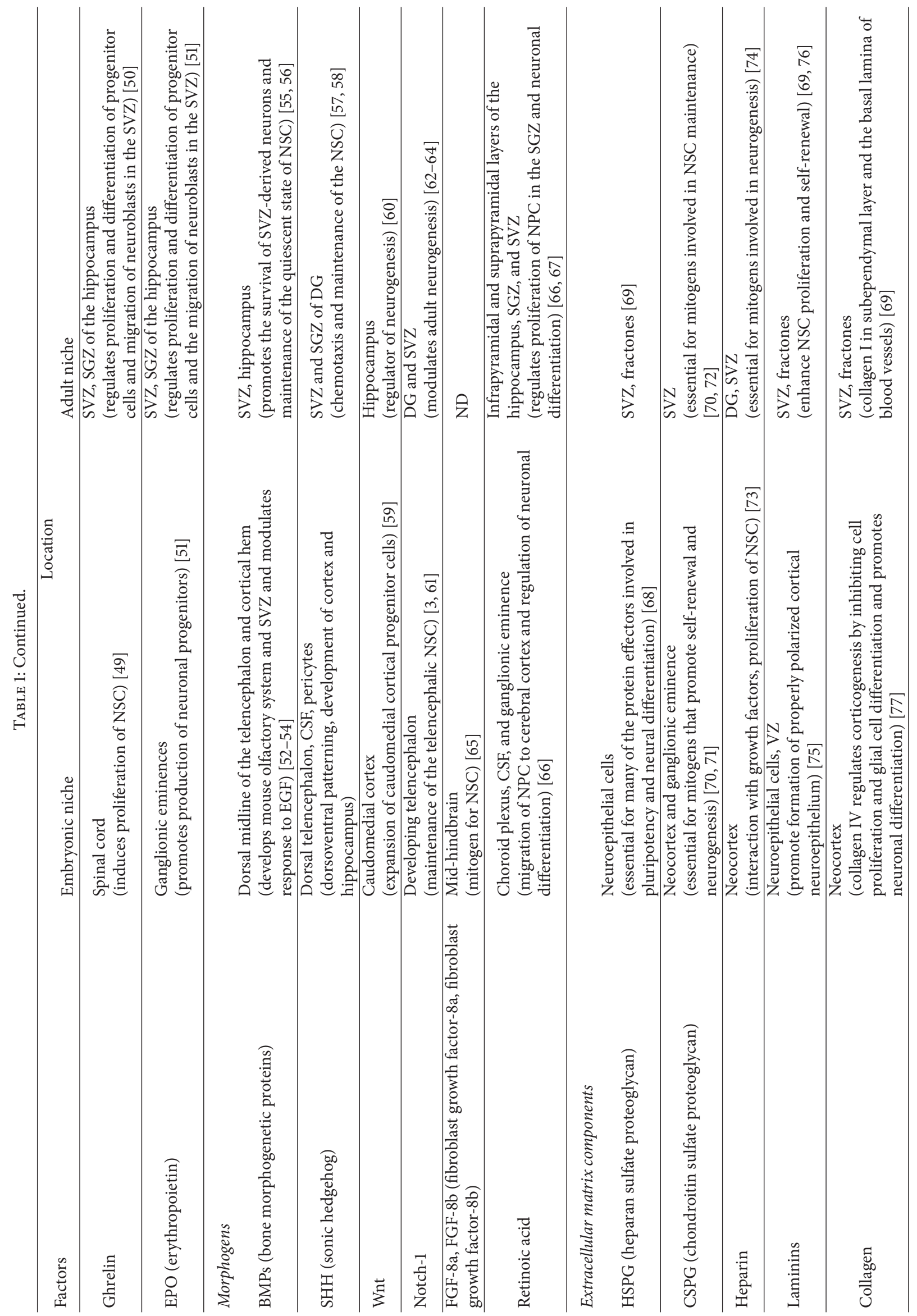




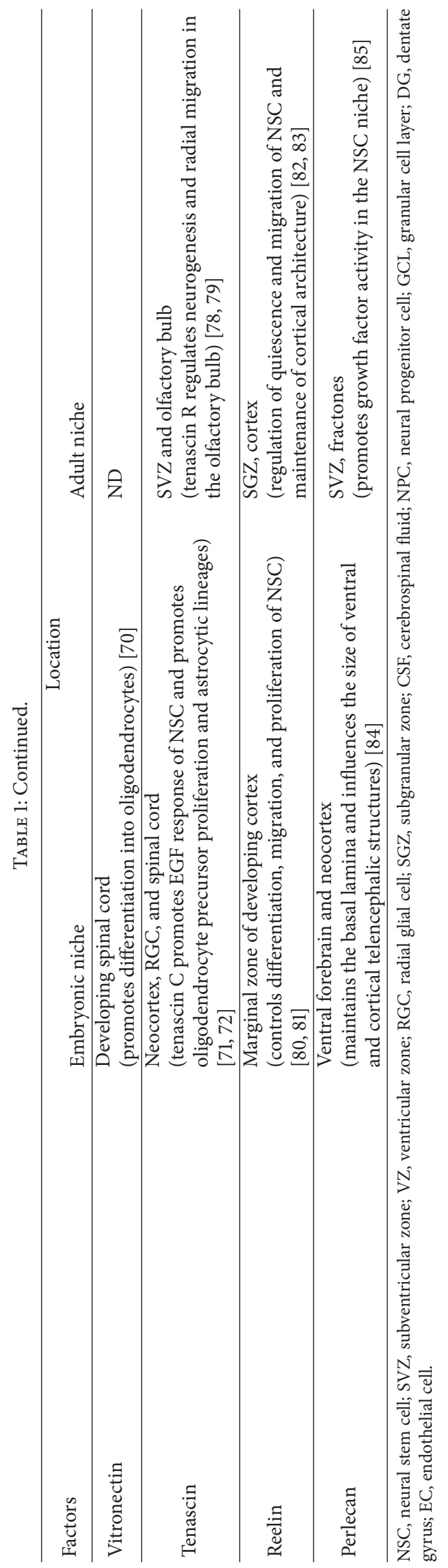


The vasculature also emerges as an important and integral component in the adult stem cell niches of both the hippocampus and SVZ [102, 103]. There is increasing evidence showing a dense network of blood vessels in the hippocampus that spans beneath the RGCs and dorsal to the SVZ in the lateral ventricles. This network is closely associated with the NSCs (including the TAPCs) and has long processes oriented along the neuroblast chain and within the microglia cells [104]. It has been shown that vasculature interactions promote the neuroproliferation and neuroprotection of the NSCs and the migration of astroglial cells through the secretion of regulatory factors in an autocrine or paracrine manner $[5,105]$. Transcriptome analysis of endothelial cells of the CNS shows the presence of several factors involved in neurogenic niche [106]. VEGF and TGFbetal are synthesized and secreted by endothelial vascular cells in the SVZ [36] and VEGF is also secreted by NSCs in the hippocampal neurogenic niche [107].

A great variety of factors active in the NSCs niche modulate the components of this site, with some of them preventing terminal differentiation and preserving the NSCs pool. A highly conserved secreted protein with a determinant role during the dorsoventral patterning of the neural tube, $\mathrm{Shh}$, is an example of such a factor. Its mutation during embryo development leads to a reduction of telencephalon and diencephalon [108] and its ectopic expression increases the generation of oligodendrocytes [109]. On the other hand, Shh is involved in maintaining the pool of progenitor cells in the postnatal brain [110].

Another factor, Notchl, is a transmembrane protein of the Notch family of proteins playing a variety of roles during development. Notchl induces the expression of transcriptional repressor genes such as Hes1, leading to the repression of proneural gene expression and the maintenance of the NSCs [105]. The importance of the Notch signaling requirement has been shown in inducible knockout mice where stem cell self-renewal and expansion are disrupted leading to neural stem cells depletion [105]. Bone morphogenetic proteins (BMPs), members of the TGF $\beta$ superfamily first identified by their role in bone induction [111], and the highly conserved Wnt proteins are all secreted proteins identified as morphogens due to their concentration dependent role during development. However, they also play a critical role in maintaining adult NSCs niches, activating the proliferation of type B astrocytes, the transit-amplifying type $C$ cells in the SVZ, and neurogenesis in the SVZ [7].

The basal lamina and ECM provide both structural shape and mechanical support for the developing and adult nervous systems [93]. These components of the neurogenic niche act as a scaffold for the incorporation of a variety of ECM molecules and growth factors. Some of the most important ECMs that play a role in the regulation of the biology of the NSCs and progenitors cells are laminin, collagen IV, nidogen, perlecan, the glycoprotein tenascin $\mathrm{C}$, the chondroitin sulfate proteoglycans (CSPG), and the heparan sulfate proteoglycans (HSPG) [112].

Laminin is an ECM heterotrimeric protein located in the lateral ventricular wall of the SVZ. In the mammalian brain and spinal cord, the basal lamina in the neurogenic site forms branches, or "finger-like processes," called fractones, that extend from the ependymal cells and blood vessels. Laminin and its receptor $\alpha 6 \beta 1$ integrin have been detected in these structures in the NSCs of the SVZ that lie near the vascular cells [87]. Additionally, heparan sulfate, collagen IV, nidogen, and perlecan have been described as components of the fractones that make contact with the transit-amplifying cells, suggesting that, in combination with growth factors, these structures have a role in adult neurogenesis. Specifically, HSPG, CSPG, and perlecan bind to growth factors such as FGF-2, a potent mitogenic factor for the NSCs, suggesting that these ECM components promote growth factor activity in the NSCs niche [113].

Secreted by type B cells, the astrocytes surrounding migratory type A cells, and the RGC in embryos, tenascin $\mathrm{C}$ is a major component of the ECM in the adult SVZ [114]. Tenascin C regulates the expression of EGF receptors in the embryonic NSCs and has been reported to alter cell response to mitogenic growth factors by enhancing sensitivity to FGF-2 and promoting EGF acquisition $[115,116]$. Tenascin $\mathrm{C}$ also regulates oligodendrocyte precursor proliferation, while the isoform tenascin $\mathrm{R}$ induces the maturation of oligodendrocyte precursors [114].

Reelin is a large ECM glycoprotein that plays an important role not only in neuronal migration during cortex development [117] but also in the NSC niche, where it is expressed in the SGZ in adult hippocampus and regulates NSCs maintenance and migration $[82,118]$.

Proteins that act as neuronal guidance factors are also associated with the regulation of the adult neurogenic niche. The Eph/ephrin receptor-ligand complex is large class of membrane associated receptors and ligands that are involved in axon guidance [119] and mediate the cell-to-cell signaling that promotes the proliferation of the NPC in the SVZ [119, 120]. Netrins are a laminin-related family of proteins that act as a guidance cue for neuronal projection and have a role in inducing the migration of NSCs during cerebellar development [121]. Recently, Netrin-4 was found to interact with components of the ECM in a complex that is able to control the proliferation of the adult NSCs and their migration to the mouse olfactory bulb [122].

Altogether, this evidence suggests that ECM components and soluble proteins regulate the biology of the NSCs in the neurogenic niche.

\section{Biocompatible Substrates for Mimicking the Neural Stem Cell Niche}

The growing body of evidence supporting the influence of the extracellular environment on stem cells raises the question as to whether in vitro culture conditions have the optimal characteristics for growing stem cells outside the body. Evidence is beginning to show that constructing in vitro microenvironments that incorporate some of the niche elements where stem cells lie in vivo could be advantageous to the understanding of stem cell biology and possible applications in regenerative medicine [2, 90, 123-125]. 
Evidence has shown that extracellular environmental characteristics such as protein composition, protein anchoring density, stiffness, and topography are important parameters to consider $[2,126]$. Polymeric biomaterials can be designed and modified to obtain compatibility characteristics with cells and tissues and to provide substrates, cells, and proteins. Compatible materials can be functionalized to provide bioactive proteins and peptides that signal cells to attach, proliferate, or differentiate and can modulate physical characteristics such as stiffness or topography, even at a nanometric scale [93, 127].

There are two main approaches for the use of biomaterials: as delivery vectors for proteins and growth factors with important effects in stem cell biology and as scaffolds for the manipulation of cell characteristics or for improving viability. More recent studies are using both approaches to design more accurate scaffolds or substrates, such as bioactive polymers with multivalent ligands, or 3D substrates with several crosslinking densities that are functionalized using active peptides $[3,93,128,129]$.

\section{Bioactive Factors Coupled to Compatible Substrates}

As mentioned before, in vivo growth factors are coupled to the ECM of the neurogenic niche, thus forming site specific regions of active factors. Growth factors are coupled by electrostatic interactions with ECM proteins such as glycosaminoglycans, which are one of the most abundant components of the ECM, thus regulating growth factor accessibility to cells [130].

Polymeric materials are usually inert and do not have chemical interactions with either cells or proteins, a property which improves biocompatibility in that it impairs the adsorption of nonspecific proteins, avoiding the recognition by innate immunity system $[131,132]$. However, bioactive peptides or proteins can be coupled to polymeric materials to support cell adhesion, viability, stemness, or differentiation and can be used as either delivery vectors or scaffolds through the coupling of specific cell adhesion proteins or peptides in $2 \mathrm{D}$ or $3 \mathrm{D}$ cultures $[123,128,133-135]$.

The use of biomaterials for the delivery of growth factors offers the possibility of controlling the place and rate of delivery and avoiding unspecific or pleiotropic effects. An important issue to consider is whether to deliver growth factors by releasing them or coupling them to the polymer. It has been shown that EGF, covalently attached to a substrate, leads to a greater expansion of human NPC as compared to soluble EGF [136], while platelet derived growth factor (PDGF), coupled to an agarose hydrogel, induces NPC differentiation into oligodendrocytes. However, the degree of the expression of myelin oligodendrocyte glycoprotein (MOG) is higher when the NPCs are exposed to soluble PDGF [137]. Covalently linked growth factors cannot be internalized by cells, meaning that their activity and function could be disrupted. Some actively released scaffolds are being developed in response to these problems, such as the heparin functionalized poly(ethylene glycol) (PEG) hydrogels [138, 139 ] and fibrin gels with growth factors coupled via heparin binding [140]. In this latter approach, the simultaneous release of neurotrophin-3 (NT-3) and PDGF improved neural induction and decreased astrocyte differentiation, indicating that a biomimetic scaffold could be designed to use several growth factors with specific kinetic release and dosages [129].

The potential of biomimetic scaffolds that provide and expose cells to growth factors for in vivo application has been recently shown using hyaluronic acid gels functionalized with ephrin B2 and Shh. Interestingly, a multivalent polymer was designed to cluster ephrin receptors which substantially increased the quantity of new neurons formed in an adult neurogenic zone, such as the hippocampus, and in nonneurogenic zones, such as the cortex and striatum. Neurogenic activity was also induced in geriatric rodents, with decreased neurogenesis in the hippocampal region [3]. Although there remain many aspects to consider before the clinical application of this strategy, it is evident that the characterization of neurogenic niches and their application in compatible bioactive materials could be a promising approach.

Cell-material interaction is crucial for the modulation of cell behavior. Polymeric materials can also be functionalized to expose peptides, adhesion molecules, or chemical groups that mimic those in cells and the ECM and exert their function through specific ligand-receptor recognition, or electrostatic interaction. The Arg-Gly-Asp (RGD) tripeptide motif present in ECM components, such as laminin, can modify adult hippocampal NSCs proliferation and differentiation $[126,141]$, with $-\mathrm{SO}_{3} \mathrm{H}$ exposed groups favoring the differentiation of embryonic NSCs into oligodendrocytes, while $-\mathrm{NH}_{2}$ exposed groups induce neuronal differentiation [142]. Functionalized polymers can be used as scaffolds to improve NSCs transplantation and thus support their survival and integration into brain tissue, especially when large tissue deficits are present, such as after traumatic brain injury, cerebral ischemia, or a transected spinal cord $[1,143$, 144].

\section{Stiffness, Topography, and Neural Stem Cells}

The physical properties of the extracellular environment also influence stem cell behavior. Stiffness is defined as the resistance of a material to deformation when force is applied and is mainly related to material composition and structure, while topography refers to the tridimensional shape and relief of a material, in this case at micro- or nanoscale.

Evidence has shown that physical properties can modify cell behavior and modulate stem cell differentiation capabilities by modulating gene expression, integrin clustering, the formation of cell adhesion, and cytoskeleton regulation [8, 145-147].

Although brain stiffness has been difficult to measure and despite the variation in the data reported according to the technique used, it has been accepted that the brain is one of the softest tissues of the body. Brain stiffness can change according to age and the area of the brain. The adult brain is stiffer than the juvenile brain $(\sim 0.040 \mathrm{kPa}$ in postnatal 10 rat brain samples versus $\sim 1.2 \mathrm{kPa}$ in adult rat brain samples). 
Interestingly, most of the cortical subregions are stiffer than the dentate gyrus and CA1 regions in the hippocampus [148]. These differences are related to the water, protein, and lipid content. Water content significantly decreases with age, while lipid and protein content increase [148]. Another important factor is the composition of the ECM, as sulfated glycosaminoglycan increases with age [97]. In a developing brain, there are also important changes in their mechanical properties, with, for example, a gradual increase in stiffness in the VZ and SVZ being closely related to neurogenic stage, neuron maturation, and ECM composition changes during development [97, 149].

Previous studies have demonstrated that mechanical properties of the substrate, in conjunction with cell adhesion ligands, can preserve the undifferentiated state of human embryonic stem cells [150] or induce differentiation in several cell phenotypes depending on the degree of stiffness [145]. In the case of neural stem cells, Leipzig and Shoichet (2009) have shown that softer substrates comprising photo cross linkable methacrylamide chitosan (MAC) hydrogels functionalized with laminin induce higher proliferation and neuronal differentiation levels for the NPCs obtained from the SVZ region of the forebrains of adult rats. In contrast, the proliferation rate decreases for the NPCs in stiffer gels, which differentiate preferably into oligodendrocytes [151]. Similarly, studies using NPCs from adult rat hippocampi showed higher proliferation rates for the NPCs in hydrogels of $\sim 0.1$ to $\sim 0.5 \mathrm{kPa}$ than in softer substrates $(\sim 0.01 \mathrm{kPa})$, reaching a proliferation peak at 1 to $4 \mathrm{kPa}$. In addition, the NPCs preferentially differentiate into the neural phenotype in soft substrates $(\sim 0.1-0.5 \mathrm{kPa})$, while glial phenotypes are predominant in stiffer substrates $(\sim 1-10 \mathrm{kPa})$ [152]. Notably, the influence of soft substrates in neuronal differentiation is maintained in $3 \mathrm{D}$ cultures when the NPCs from adult hippocampi are grown in alginate hydrogels [153].

An interesting fact is that NPCs reach high proliferation and neuronal differentiation levels in substrates with low stiffness that are similar to those reported for brain tissue. However, the influence of soft gel substrates on embryonic NPC differentiation seems to be different, in that it has been shown that glial differentiation is enhanced in soft polydimethylsiloxane gels (PDMS), while neuronal differentiation is not affected by soft gels, as previously described [154]. These differences could be attributed to the origin or stage of development of the NPCs, or even the characteristics of the substrate, as reported previously by Trappmann et al. (2012) [147].

The effects of substrate stiffness can be mediated by the modulation of gene expression, as reported earlier using mesenchymal stem cells (MSCs). When MSCs are grown for longer periods of time on stiffer substrates, the proosteogenic genes are expressed in a nonreversible way. However, when they are grown for short periods of time on the same substrate, the MCSs are still able to reverse the expression of proosteogenic genes and begin to express neurogenic genes, which shows evidence of a sort of mechanical memory that could have important implications for the way stem cells are being grown and expanded in vitro [8].
The micro- and nanoscale topography of a substrate have been shown to be another important factor for the manipulation of stem cell behavior. Topography can be altered, using pillars, grooves, pits, or fibers to modify cell orientation and cytoskeleton arrangement. The microscale distribution of cell adhesion points and, therefore, the manipulation of cell shape has been shown to be crucial to the direction of MSC differentiation toward osteogenic or adipogenic lineage. These effects are mediated by actin-myosin tension [155]. Fiber diameter can also influence NSCs differentiation; laminincoated electrospun polyethersulfone (PES) fiber meshes of $283 \mathrm{~nm}$ increased oligodendrocyte differentiation by $40 \%$, while $749 \mathrm{~nm}$ fibers increased neuronal differentiation by $20 \%$ as compared with culture plates [156]. Aligned fiber substrates of $480 \mathrm{~nm}$ upregulate neuronal differentiation through the induction of $\mathrm{Wnt} / \beta$ catenin signaling, which is a crucial pathway during neurogenesis in embryos and adults and is more favorable to the survival of neuronal cells as compared to the oligodendrocytes [124]. It has also been shown that micropatterned substrates with aligned microgrooves functionalized with laminin align the direction of hippocampal NSCs growth and facilitate their differentiation into neurons when they are cocultured with astrocytes [157].

Although the multiple approaches to the physical and chemical manipulation of biocompatible substrates show their capability to manipulate NSCs behavior, there are still several characteristics that must be considered, such as the complexity of the interrelation of multiple signals and how these can affect NSCs behavior depending on their origin and the intrinsic stem cell characteristics.

\section{Conclusions}

The study of the numerous elements present in the neurogenic niche and how they interact with stem cell behavior contributes to understanding the importance of extrinsic signals for NSCs destiny. This knowledge is being used to mimic the neurogenic niche for in vitro and in vivo applications. Although the results obtained up to now show promise, a more accurate biomimetic substrate for in vitro studies and regenerative medicine is still a long way off. Several factors must be taken into account, such as the soluble factors and ECM components present in the niche and the physical properties of the substrate. The type and the origin of the stem cells intended to provide a niche must also be considered. The ideal biomimetic scaffold should, therefore, incorporate some of the main factors that control stem cell behavior. Multidisciplinary approaches to developing the most accurate niche-like substrates and to understanding their biological implications are a fascinating field that will help develop stem cells knowledge.

\section{Conflict of Interests}

The authors declare that there is no conflict of interests regarding the publication of this paper. 


\section{References}

[1] H. Kim, M. J. Cooke, and M. S. Shoichet, "Creating permissive microenvironments for stem cell transplantation into the central nervous system," Trends in Biotechnology, vol. 30, no. 1, pp. 55-63, 2012.

[2] S. W. Lane, D. A. Williams, and F. M. Watt, "Modulating the stem cell niche for tissue regeneration," Nature Biotechnology, vol. 32, no. 8, pp. 795-803, 2014.

[3] A. Conway and D. V. Schaffer, "Biomaterial microenvironments to support the generation of new neurons in the adult brain," Stem Cells, vol. 32, no. 5, pp. 1220-1229, 2014.

[4] L. De Filippis and E. Binda, "Concise review: self-renewal in the central nervous system: neural stem cells from embryo to adult," Stem Cells Translational Medicine, vol. 1, no. 4, pp. 298308, 2012.

[5] C. S. Bjornsson, M. Apostolopoulou, Y. Tian, and S. Temple, "It takes a village: constructing the neurogenic niche," Developmental Cell, vol. 32, no. 4, pp. 435-446, 2015.

[6] I. Kazanis, J. Lathia, L. Moss, and C. ffrench-Constant, "The neural stem cell microenvironment," in StemBook, pp. 1-26, 2008.

[7] N. Urbán and F. Guillemot, "Neurogenesis in the embryonic and adult brain: same regulators, different roles," Frontiers in Cellular Neuroscience, vol. 8, article 396, 2014.

[8] C. Yang, M. W. Tibbitt, L. Basta, and K. S. Anseth, "Mechanical memory and dosing influence stem cell fate," Nature Materials, vol. 13, no. 6, pp. 645-652, 2014.

[9] H. Liu, X. Xue, H. Shi, L. Qi, and D. Gong, "Osthole upregulates bdnf to enhance adult hippocampal neurogenesis in APP/PS1 transgenic mice," Biological \& Pharmaceutical Bulletin, vol. 38, no. 10, pp. 1439-1449, 2015.

[10] Z. Wei, J. Liao, F. Qi, Z. Meng, and S. Pan, "Evidence for the contribution of BDNF-TrkB signal strength in neurogenesis: an organotypic study," Neuroscience Letters, vol. 606, pp. 48-52, 2015.

[11] A. Hasegawa, M. Naruse, S. Hitoshi, Y. Iwasaki, H. Takebayashi, and K. Ikenaka, "Regulation of glial development by cystatin C," Journal of Neurochemistry, vol. 100, no. 1, pp. 12-22, 2007.

[12] P. Taupin, "Adult neural stem cells, neurogenic niches, and cellular therapy," Stem Cell Reviews, vol. 2, no. 3, pp. 213-220, 2006.

[13] D. Maric, A. F. Pla, H. C. Yoong, and J. L. Barker, "Self-renewing and differentiating properties of cortical neural stem cells are selectively regulated by basic fibroblast growth factor (FGF) signaling via specific FGF receptors," Journal of Neuroscience, vol. 27, no. 8, pp. 1836-1852, 2007.

[14] Y. Arsenijevic, S. Weiss, B. Schneider, and P. Aebischer, "Insulinlike growth factor-1 is necessary for neural stem cell proliferation and demonstrates distinct actions of epidermal growth factor and fibroblast growth factor-2," The Journal of Neuroscience, vol. 21, no. 18, pp. 7194-7202, 2001.

[15] C. Bondy and W.-H. Lee, "Correlation between insulin-like growth factor (IGF)-binding protein 5 and IGF-I gene expression during brain development," Journal of Neuroscience, vol. 13, no. 12, pp. 5092-5104, 1993.

[16] R. D. Hodge, A. J. D’Ercole, and J. R. O’Kusky, “Increased expression of insulin-like growth factor-I (IGF-I) during embryonic development produces neocortical overgrowth with differentially greater effects on specific cytoarchitectonic areas and cortical layers," Developmental Brain Research, vol. 154, no. 2, pp. 227-237, 2005.
[17] M. K. Lehtinen, M. W. Zappaterra, X. Chen et al., "The cerebrospinal fluid provides a proliferative niche for neural progenitor cells," Neuron, vol. 69, no. 5, pp. 893-905, 2011.

[18] Z. Salehi, F. Mashayekhi, M. Naji, and S. Pandamooz, "Insulinlike growth factor-1 and insulin-like growth factor binding proteins in cerebrospinal fluid during the development of mouse embryos," Journal of Clinical Neuroscience, vol. 16, no. 7, pp. 950-953, 2009.

[19] M. F. Anderson, M. A. I. Åberg, M. Nilsson, and P. S. Eriksson, "Insulin-like growth factor-I and neurogenesis in the adult mammalian brain," Developmental Brain Research, vol. 134, no. 1-2, pp. 115-122, 2002.

[20] M. Pérez-Martín, M. Cifuentes, J. M. Grondona et al., "IGFI stimulates neurogenesis in the hypothalamus of adult rats," European Journal of Neuroscience, vol. 31, no. 9, pp. 1533-1548, 2010.

[21] T. J. Kilpatrick and P. F. Bartlett, "Cloned multipotential precursors from the mouse cerebrum require FGF-2, whereas glial restricted precursors are stimulated with either FGF-2 or EGF," Journal of Neuroscience, vol. 15, no. 5, pp. 3653-3661, 1995.

[22] B. A. Reynolds, W. Tetzlaff, and S. Weiss, "A multipotent EGFresponsive striatal embryonic progenitor cell produces neurons and astrocytes," Journal of Neuroscience, vol. 12, no. 11, pp. 45654574, 1992.

[23] C. Giachino, O. Basak, S. Lugert et al., "Molecular diversity subdivides the adult forebrain neural stem cell population," STEM CELLS, vol. 32, no. 1, pp. 70-84, 2014.

[24] M. Maxwell, T. Galanopoulos, J. Neville-Golden, E. T. HedleyWhyte, and H. N. Antoniades, "Cellular localization of PDGF mRNAs in developing human forebrain," Neuropathology and Applied Neurobiology, vol. 24, no. 5, pp. 337-345, 1998.

[25] N. P. Pringle, H. S. Mudhar, E. J. Collarini, and W. D. Richardson, "PDGF receptors in the rat CNS: during late neurogenesis, PDGF alpha-receptor expression appears to be restricted to glial cells of the oligodendrocyte lineage," Development, vol. 115, no. 2, pp. 535-551, 1992.

[26] L. Moore, J. M. Bain, J. M. Loh, and S. W. Levison, "PDGFresponsive progenitors persist in the subventricular zone across the lifespan," ASN Neuro, vol. 6, no. 2, Article ID e00137, 2014.

[27] C. Andreu-Agulló, J. M. Morante-Redolat, A. C. Delgado, and I. Fariñas, "Vascular niche factor PEDF modulates notchdependent stemness in the adult subependymal zone," Nature Neuroscience, vol. 12, no. 12, pp. 1514-1523, 2009.

[28] C. Ramírez-Castillejo, F. Sánchez-Sánchez, C. Andreu-Agulló et al., "Pigment epithelium-derived factor is a niche signal for neural stem cell renewal," Nature Neuroscience, vol. 9, no. 3, pp. 331-339, 2006.

[29] Y. Shi and J.-P. Liu, "Gdf11 facilitates temporal progression of neurogenesis in the developing spinal cord," Journal of Neuroscience, vol. 31, no. 3, pp. 883-893, 2011.

[30] N. Vanbekbergen, M. Hendrickx, and L. Leyns, "Growth differentiation factor 11 is an encephalic regionalizing factor in neural differentiated mouse embryonic stem cells," BMC Research Notes, vol. 7, no. 1, article 766, 2014.

[31] C. Carrillo-García, S. Prochnow, I. K. Simeonova et al., "Growth/differentiation factor 15 promotes EGFR signalling, and regulates proliferation and migration in the hippocampus of neonatal and young adult mice," Development, vol. 141, no. 4, pp. 773-783, 2014.

[32] A. J. Salgado, J. C. Sousa, B. M. Costa et al., "Mesenchymal stem cells secretome as a modulator of the neurogenic niche: basic 
insights and therapeutic opportunities," Frontiers in Cellular Neuroscience, vol. 9, article 249, 2015.

[33] S. Boku, S. Nakagawa, N. Takamura et al., "GDNF facilitates differentiation of the adult dentate gyrus-derived neural precursor cells into astrocytes via STAT3," Biochemical and Biophysical Research Communications, vol. 434, no. 4, pp. 779-784, 2013.

[34] Z. Kokaia, M. S. Airaksinen, A. Nanobashvili et al., "GDNF family ligands and receptors are differentially regulated after brain insults in the rat," European Journal of Neuroscience, vol. 11, no. 4, pp. 1202-1216, 1999.

[35] J. Stipursky, D. Francis, R. S. Dezonne et al., "TGF- $\beta 1$ promotes cerebral cortex radial glia-astrocyte differentiation in vivo," Frontiers in Cellular Neuroscience, vol. 8, article 393, 2014.

[36] Q. Li, M. C. Ford, E. B. Lavik, and J. A. Madri, "Modeling the neurovascular niche: VEGF- and BDNF-mediated crosstalk between neural stem cells and endothelial cells: an in vitro study," Journal of Neuroscience Research, vol. 84, no. 8, pp. 16561668, 2006.

[37] K. Jin, Y. Zhu, Y. Sun, X. O. Mao, L. Xie, and D. A. Greenberg, "Vascular endothelial growth factor (VEGF) stimulates neurogenesis in vitro and in vivo," Proceedings of the National Academy of Sciences of the United States of America, vol. 99, no. 18, pp. 11946-11950, 2002.

[38] N. Kaneko, E. Kako, and K. Sawamoto, "Enhancement of ventricular-subventricular zone-derived neurogenesis and oligodendrogenesis by erythropoietin and its derivatives," Frontiers in Cellular Neuroscience, vol. 7, article 235, 2013.

[39] C. Gregg and S. Weiss, "CNTF/LIF/gp130 receptor complex signaling maintains a $\mathrm{VZ}$ precursor differentiation gradient in the developing ventral forebrain," Development, vol. 132, no. 3, pp. 565-578, 2005.

[40] T. Shimazaki, T. Shingo, and S. Weiss, "The ciliary neurotrophic factor/leukemia inhibitory factor/gp130 receptor complex operates in the maintenance of mammalian forebrain neural stem cells," The Journal of Neuroscience, vol. 21, no. 19, pp. 7642-7653, 2001.

[41] J. G. Emsley and T. Hagg, "Endogenous and exogenous ciliary neurotrophic factor enhances forebrain neurogenesis in adult mice," Experimental Neurology, vol. 183, no. 2, pp. 298-310, 2003.

[42] S. Müller, B. P. S. Chakrapani, H. Schwegler, H.-D. Hokmann, and M. Kirsch, "Neurogenesis in the dentate gyrus depends on ciliary neurotrophic factor and signal transducer and activator of transcription 3 signaling," STEM CELLS, vol. 27, no. 2, pp. 431-441, 2009.

[43] S. Bauer and P. H. Patterson, "Leukemia inhibitory factor promotes neural stem cell self-renewal in the adult brain," Journal of Neuroscience, vol. 26, no. 46, pp. 12089-12099, 2006.

[44] B. E. Deverman and P. H. Patterson, "Exogenous leukemia inhibitory factor stimulates oligodendrocyte progenitor cell proliferation and enhances hippocampal remyelination," The Journal of Neuroscience, vol. 32, no. 6, pp. 2100-2109, 2012.

[45] R. Ajo, L. Cacicedo, C. Navarro, and F. Sánchez-Franco, "Growth hormone action on proliferation and differentiation of cerebral cortical cells from fetal rat," Endocrinology, vol. 144, no. 3, pp. 1086-1097, 2003.

[46] C. Regalado-Santiago, M. L. López-Meraz, J. Santiago-García, C. Fernández-Pomares, and E. Juárez-Aguilar, "Growth hormone $(\mathrm{GH})$ is a survival rather than a proliferative factor for embryonic striatal neural precursor cells," Growth Hormone and IGF Research, vol. 23, no. 5, pp. 179-186, 2013.

[47] D. G. Blackmore, B. A. Reynolds, M. G. Golmohammadi et al., "Growth hormone responsive neural precursor cells reside within the adult mammalian brain," Scientific Reports, vol. 2, article 250, 2012.

[48] S. McLenachan, M.-G. Lum, M. J. Waters, and A. M. Turnley, "Growth hormone promotes proliferation of adult neurosphere cultures," Growth Hormone and IGF Research, vol. 19, no. 3, pp. 212-218, 2009.

[49] M. Sato, K. Nakahara, S. Goto et al., "Effects of ghrelin and des-acyl ghrelin on neurogenesis of the rat fetal spinal cord," Biochemical and Biophysical Research Communications, vol. 350, no. 3, pp. 598-603, 2006.

[50] E. Li, Y. Kim, S. Kim, T. Sato, M. Kojima, and S. Park, "Ghrelin stimulates proliferation, migration and differentiation of neural progenitors from the subventricular zone in the adult mice," Experimental Neurology, vol. 252, pp. 75-84, 2014.

[51] T. Shingo, S. T. Sorokan, T. Shimazaki, and S. Weiss, "Erythropoietin regulates the in vitro and in vivo production of neuronal progenitors by mammalian forebrain neural stem cells," Journal of Neuroscience, vol. 21, no. 24, pp. 9733-9743, 2001.

[52] Y. Furuta, D. W. Piston, and B. L. M. Hogan, "Bone morphogenetic proteins (BMPs) as regulators of dorsal forebrain development," Development, vol. 124, no. 11, pp. 2203-2212, 1997.

[53] L. Lillien and H. Raphael, "BMP and FGF regulate the development of EGF-responsive neural progenitor cells," Development, vol. 127, no. 22, pp. 4993-5005, 2000.

[54] P. Peretto, D. Cummings, C. Modena et al., "BMP mRNA and protein expression in the developing mouse olfactory system," Journal of Comparative Neurology, vol. 451, no. 3, pp. 267-278, 2002.

[55] D. A. Lim, A. D. Tramontin, J. M. Trevejo, D. G. Herrera, J. M. García-Verdugo, and A. Alvarez-Buylla, "Noggin antagonizes BMP signaling to create a niche for adult neurogenesis," Neuron, vol. 28, no. 3, pp. 713-726, 2000.

[56] H. Mira, Z. Andreu, H. Suh et al., "Signaling through BMPR-IA regulates quiescence and long-term activity of neural stem cells in the adult hippocampus," Cell Stem Cell, vol. 7, no. 1, pp. 78-89, 2010.

[57] F. Balordi and G. Fishell, "Mosaic removal of hedgehog signaling in the adult SVZ reveals that the residual wild-type stem cells have a limited capacity for self-renewal," The Journal of Neuroscience, vol. 27, no. 52, pp. 14248-14259, 2007.

[58] F. Balordi and G. Fishell, "Hedgehog signaling in the subventricular zone is required for both the maintenance of stem cells and the migration of newborn neurons," Journal of Neuroscience, vol. 27, no. 22, pp. 5936-5947, 2007.

[59] S. M. K. Lee, S. Tole, E. Grove, and A. P. McMahon, "A local Wnt-3a signal is required for development of the mammalian hippocampus," Development, vol. 127, no. 3, pp. 457-467, 2000.

[60] D.-C. Lie, S. A. Colamarino, H.-J. Song et al., "Wnt signalling regulates adult hippocampal neurogenesis," Nature, vol. 437, no. 7063, pp. 1370-1375, 2005.

[61] C. B. Chambers, Y. Peng, H. Nguyen, N. Gaiano, G. Fishell, and J. S. Nye, "Spatiotemporal selectivity of response to Notch1 signals in mammalian forebrain precursors," Development, vol. 128, no. 5, pp. 689-702, 2001.

[62] O. Basak, C. Giachino, E. Fiorini, H. R. MacDonald, and V. Taylor, "Neurogenic subventricular zone stem/progenitor cells are Notchl-dependent in their active but not quiescent state," The Journal of Neuroscience, vol. 32, no. 16, pp. 5654-5666, 2012.

[63] J. J. Breunig, J. Silbereis, F. M. Vaccarino, N. Šestan, and P. Rakic, "Notch regulates cell fate and dendrite morphology of newborn neurons in the postnatal dentate gyrus," Proceedings of 
the National Academy of Sciences of the United States of America, vol. 104, no. 51, pp. 20558-20563, 2007.

[64] F. Sun, X. Mao, L. Xie, M. Ding, B. Shao, and K. Jin, "Notch1 signaling modulates neuronal progenitor activity in the subventricular zone in response to aging and focal ischemia," Aging Cell, vol. 12, no. 6, pp. 978-987, 2013.

[65] S. M. K. Lee, P. S. Danielian, B. Fritzsch, and A. P. McMahon, "Evidence that FGF8 signalling from the midbrain-hindbrain junction regulates growth and polarity in the developing midbrain," Development, vol. 124, no. 5, pp. 959-969, 1997.

[66] B. Orsolits, A. Borsy, E. Madarász et al., "Retinoid machinery in distinct neural stem cell populations with different retinoid responsiveness," Stem Cells and Development, vol. 22, no. 20, pp. 2777-2793, 2013.

[67] T. Goodman, J. E. Crandall, S. E. Nanescu et al., "Patterning of retinoic acid signaling and cell proliferation in the hippocampus," Hippocampus, vol. 22, no. 11, pp. 2171-2183, 2012.

[68] C. E. Johnson, B. E. Crawford, M. Stavridis et al., "Essential alterations of heparan sulfate during the differentiation of embryonic stem cells to Soxl-enhanced green fluorescent protein-expressing neural progenitor cells," Stem Cells, vol. 25, no. 8, pp. 1913-1923, 2007.

[69] F. Mercier, J. T. Kitasako, and G. I. Hatton, "Anatomy of the brain neurogenic zones revisited: fractones and the fibroblast/macrophage network," Journal of Comparative Neurology, vol. 451, no. 2, pp. 170-188, 2002.

[70] J.-E. Gil, D.-H. Woo, J.-H. Shim et al., "Vitronectin promotes oligodendrocyte differentiation during neurogenesis of human embryonic stem cells," FEBS Letters, vol. 583, no. 3, pp. 561-567, 2009.

[71] T. Czopka, A. von Holst, C. Ffrench-Constant, and A. Faissner, "Regulatory mechanisms that mediate tenascin C-dependent inhibition of oligodendrocyte precursor differentiation," Journal of Neuroscience, vol. 30, no. 37, pp. 12310-12322, 2010.

[72] M. Karus, B. Denecke, C. Ffrench-Constant, S. Wiese, and A. Faissner, "The extracellular matrix molecule tenascin C modulates expression levels and territories of key patterning genes during spinal cord astrocyte specification," Development, vol. 138, no. 24, pp. 5321-5331, 2011.

[73] S. S. Deepa, Y. Umehara, S. Higashiyama, N. Itoh, and K. Sugahara, "Specific molecular interactions of oversulfated chondroitin sulfate $\mathrm{E}$ with various heparin-binding growth factors: implications as a physiological binding partner in the brain and other tissues," The Journal of Biological Chemistry, vol. 277, no. 46, pp. 43707-43716, 2002.

[74] K. Jin, Y. Sun, L. Xie et al., "Neurogenesis and aging: FGF2 and HB-EGF restore neurogenesis in hippocampus and subventricular zone of aged mice," Aging Cell, vol. 2, no. 3, pp. 175-183, 2003.

[75] J. D. Lathia, B. Patton, D. M. Eckley et al., "Patterns of laminins and integrins in the embryonic ventricular zone of the CNS," Journal of Comparative Neurology, vol. 505, no. 6, pp. 630-643, 2007.

[76] R. Belvindrah, S. Hankel, J. Walker, B. L. Patton, and U. Müller, " $\beta 1$ integrins control the formation of cell chains in the adult rostral migratory stream," Journal of Neuroscience, vol. 27, no. 10, pp. 2704-2717, 2007.

[77] S. A. Ali, I. S. Pappas, and J. G. Parnavelas, "Collagen type IV promotes the differentiation of neuronal progenitors and inhibits astroglial differentiation in cortical cell cultures," Developmental Brain Research, vol. 110, no. 1, pp. 31-38, 1998.
[78] L. S. David, M. Schachner, and A. Saghatelyan, "The extracellular matrix glycoprotein tenascin- $\mathrm{R}$ affects adult but not developmental neurogenesis in the olfactory bulb," Journal of Neuroscience, vol. 33, no. 25, pp. 10324-10339, 2013.

[79] A. Saghatelyan, A. de Chevigny, M. Schachner, and P.-M. Lledo, "Tenascin-R mediates activity-dependent recruitment of neuroblasts in the adult mouse forebrain," Nature Neuroscience, vol. 7, no. 4, pp. 347-356, 2004.

[80] J. Lakomá, L. Garcia-Alonso, and J. M. Luque, "Reelin sets the pace of neocortical neurogenesis," Development, vol. 138, no. 23, pp. 5223-5234, 2011.

[81] S. Massalini, S. Pellegatta, F. Pisati, G. Finocchiaro, M. G. Farace, and S. A. Ciafrè, "Reelin affects chain-migration and differentiation of neural precursor cells," Molecular and Cellular Neuroscience, vol. 42, no. 4, pp. 341-349, 2009.

[82] M. Sibbe, E. Kuner, D. Althof, and M. Frotscher, "Stem- and progenitor cell proliferation in the dentate gyrus of the reeler mouse," PLoS ONE, vol. 10, no. 3, Article ID e0119643, 2015.

[83] I. Hack, M. Bancila, K. Loulier, P. Carroll, and H. Cremer, "Reelin is a detachment signal in tangential chain-migration during postnatal neurogenesis," Nature Neuroscience, vol. 5, no. 10, pp. 939-945, 2002.

[84] A. Girós, J. Morante, C. Gil-Sanz, A. Fairén, and M. Costell, "Perlecan controls neurogenesis in the developing telencephalon," BMC Developmental Biology, vol. 7, article 29, 2007.

[85] A. Kerever, J. Schnack, D. Vellinga et al., "Novel extracellular matrix structures in the neural stem cell niche capture the neurogenic factor fibroblast growth factor 2 from the extracellular milieu," STEM CELLS, vol. 25, no. 9, pp. 2146-2157, 2007.

[86] A. Achilleos and P. A. Trainor, "Neural crest stem cells: discovery, properties and potential for therapy," Cell Research, vol. 22, no. 2, pp. 288-304, 2012.

[87] Q. Shen, Y. Wang, E. Kokovay et al., "Adult SVZ stem cells lie in a vascular niche: a quantitative analysis of niche cell-cell interactions," Cell Stem Cell, vol. 3, no. 3, pp. 289-300, 2008.

[88] V. Solozobova, N. Wyvekens, and J. Pruszak, "Lessons from the embryonic neural stem cell niche for neural lineage differentiation of pluripotent stem cells," Stem Cell Reviews and Reports, vol. 8, no. 3, pp. 813-829, 2012.

[89] G.-L. Ming and H. Song, "Adult neurogenesis in the mammalian brain: significant answers and significant questions," Neuron, vol. 70, no. 4, pp. 687-702, 2011.

[90] R. Lin and L. Iacovitti, "Classic and novel stem cell niches in brain homeostasis and repair," Brain Research, 2015.

[91] A. Alvarez-Buylla, M. Kohwi, T. M. Nguyen, and F. T. Merkle, "The heterogeneity of adult neural stem cells and the emerging complexity of their niche," Cold Spring Harbor Symposia on Quantitative Biology, vol. 73, pp. 357-365, 2008.

[92] F. Doetsch, "A niche for adult neural stem cells," Current Opinion in Genetics and Development, vol. 13, no. 5, pp. 543550, 2003.

[93] F. Gattazzo, A. Urciuolo, and P. Bonaldo, "Extracellular matrix: a dynamic microenvironment for stem cell niche," Biochimica et Biophysica Acta-General Subjects, vol. 1840, no. 8, pp. 25062519, 2014.

[94] H. B. Stolp and Z. Molnár, "Neurogenic niches in the brain: help and hindrance of the barrier systems," Frontiers in Neuroscience, vol. 9, article 20, 2015.

[95] F. D. Miller and A. Gauthier-Fisher, "Home at last: neural stem cell niches defined," Cell Stem Cell, vol. 4, no. 6, pp. 507-510, 2009. 
[96] C. Nern and S. Momma, "The realized niche of adult neural stem cells," Stem Cell Reviews, vol. 2, no. 3, pp. 233-240, 2006.

[97] K. Franze, "The mechanical control of nervous system development," Development, vol. 140, no. 15, pp. 3069-3077, 2013.

[98] C. Kiecker and A. Lumsden, "Compartments and their boundaries in vertebrate brain development," Nature Reviews Neuroscience, vol. 6, no. 7, pp. 553-564, 2005.

[99] Y. Jin, N. Raviv, A. Barnett, N. C. Bambakidis, E. Filichia, and Y. Luo, "The shh signaling pathway is upregulated in multiple cell types in cortical ischemia and influences the outcome of stroke in an animal model," PLOS ONE, vol. 10, no. 4, Article ID e0124657, 2015.

[100] S. Singh and D. J. Solecki, "Polarity transitions during neurogenesis and germinal zone exit in the developing central nervous system," Frontiers in Cellular Neuroscience, vol. 9, article 62, 2015.

[101] C. M. Nielsen and S. M. Dymecki, "Sonic hedgehog is required for vascular outgrowth in the hindbrain choroid plexus," Developmental Biology, vol. 340, no. 2, pp. 430-437, 2010.

[102] M. Tavazoie, L. Van der Veken, V. Silva-Vargas et al., "A specialized vascular niche for adult neural stem cells," Cell Stem Cell, vol. 3, no. 3, pp. 279-288, 2008.

[103] P. A. Riquelme, E. Drapeau, and F. Doetsch, "Brain microecologies: neural stem cell niches in the adult mammalian brain," Philosophical Transactions of the Royal Society B: Biological Sciences, vol. 363, no. 1489, pp. 123-137, 2008.

[104] C. Lee, J. Hu, S. Ralls et al., "The molecular profiles of neural stem cell niche in the adult subventricular zone," PLOS ONE, vol. 7, no. 11, Article ID e50501, 2012.

[105] I. Imayoshi, M. Sakamoto, M. Yamaguchi, K. Mori, and R. Kageyama, "Essential roles of Notch signaling in maintenance of neural stem cells in developing and adult brains," The Journal of Neuroscience, vol. 30, no. 9, pp. 3489-3498, 2010.

[106] R. Daneman, L. Zhou, D. Agalliu, J. D. Cahoy, A. Kaushal, and B. A. Barres, "The mouse blood-brain barrier transcriptome: a new resource for understanding the development and function of brain endothelial cells," PLoS ONE, vol. 5, no. 10, Article ID e13741, 2010.

[107] E. D. Kirby, A. A. Kuwahara, R. L. Messer, and T. Wyss-Coray, "Adult hippocampal neural stem and progenitor cells regulate the neurogenic niche by secreting VEGF," Proceedings of the National Academy of Sciences, vol. 112, no. 13, pp. 4128-4133, 2015.

[108] N. Gaiano, J. D. Kohtz, D. H. Turnbull, and G. Fishell, "A method for rapid gain-of-function studies in the mouse embryonic nervous system," Nature Neuroscience, vol. 2, no. 9, pp. 812-819, 1999.

[109] S. Nery, H. Wichterle, and G. Fishell, "Sonic hedgehog contributes to oligodendrocyte specification in the mammalian forebrain," Development, vol. 128, no. 4, pp. 527-540, 2001.

[110] R. Machold, S. Hayashi, M. Rutlin et al., "Sonic hedgehog is required for progenitor cell maintenance in telencephalic stem cell niches," Neuron, vol. 39, pp. 937-950, 2003.

[111] A. M. Bond, O. G. Bhalala, and J. A. Kessler, "The dynamic role of bone morphogenetic proteins in neural stem cell fate and maturation," Developmental Neurobiology, vol. 72, no. 7, pp. 1068-1084, 2012.

[112] A. Wade, A. McKinney, and J. J. Phillips, "Matrix regulators in neural stem cell functions," Biochimica et Biophysica ActaGeneral Subjects, vol. 1840, no. 8, pp. 2520-2525, 2014.
[113] A. Purushothaman, K. Sugaharas, and A. Faissner, "Chondroitin sulfate "wobble motifs" modulate maintenance and differentiation of neural stem cells and their progeny," Journal of Biological Chemistry, vol. 287, no. 5, pp. 2935-2942, 2012.

[114] U. Theocharidis, K. Long, C. ffrench-Constant, and A. Faissner, "Regulation of the neural stem cell compartment by extracellular matrix constituents," Progress in Brain Research, vol. 214, pp. 3-28, 2014.

[115] J. Garwood, E. Garcion, A. Dobbertin et al., "The extracellular matrix glycoprotein Tenascin-C is expressed by oligodendrocyte precursor cells and required for the regulation of maturation rate, survival and responsiveness to platelet-derived growth factor," European Journal of Neuroscience, vol. 20, no. 10, pp. 2524-2540, 2004.

[116] R. Chiquet-Ehrismann, G. Orend, M. Chiquet, R. P. Tucker, and K. S. Midwood, "Tenascins in stem cell niches," Matrix Biology, vol. 37, pp. 112-123, 2014.

[117] E. Förster, "Reelin, neuronal polarity and process orientation of cortical neurons," Neuroscience, vol. 269, pp. 102-111, 2014.

[118] G. D’Arcangelo, G. G. Miao, S.-C. Chen, H. D. Soares, J. I. Morgan, and T. Curran, "A protein related to extracellular matrix proteins deleted in the mouse mutant reeler," Nature, vol. 374, no. 6524, pp. 719-723, 1995.

[119] J. Rodger, L. Salvatore, and P. Migani, "Should i stay or should i go? Ephs and ephrins in neuronal migration," NeuroSignals, vol. 20, no. 3, pp. 190-201, 2012.

[120] T. Nomura, C. Göritz, T. Catchpole, M. Henkemeyer, and J. Frisén, "EphB signaling controls lineage plasticity of adult neural stem cell niche cells," Cell Stem Cell, vol. 7, no. 6, pp. 730$743,2010$.

[121] K. L. W. Sun, J. P. Correia, and T. E. Kennedy, "Netrins: versatile extracellular cues with diverse functions," Development, vol.138, no. 11, pp. 2153-2169, 2011.

[122] F. I. Staquicini, E. Dias-Neto, J. Li et al., "Discovery of a functional protein complex of netrin-4, laminin $\gamma 1$ chain, and integrin $\alpha 6 \beta 1$ in mouse neural stem cells," Proceedings of the National Academy of Sciences of the United States of America, vol. 106, no. 8, pp. 2903-2908, 2009.

[123] K. Lee, E. A. Silva, and D. J. Mooney, "Growth factor deliverybased tissue engineering: general approaches and a review of recent developments," Journal of the Royal Society Interface, vol. 8, no. 55, pp. 153-170, 2011.

[124] S. H. Lim, X. Y. Liu, H. Song, K. J. Yarema, and H.-Q. Mao, "The effect of nanofiber-guided cell alignment on the preferential differentiation of neural stem cells," Biomaterials, vol. 31, no. 34, pp. 9031-9039, 2010.

[125] S. L. Yao, X. Liu, X. M. Wang, A. Merolli, X. B. Chen, and F. Z. Cui, "Directing neural stem cell fate with biomaterial parameters for injured brain regeneration," Progress in Natural Science: Materials International, vol. 23, pp. 103-1112, 2013.

[126] K. Saha, E. F. Irwin, J. Kozhukh, D. V. Schaffer, and K. E. Healy, "Biomimetic interfacial interpenetrating polymer networks control neural stem cell behavior," Journal of Biomedical Materials Research Part A, vol. 81, no. 1, pp. 240-249, 2007.

[127] L. Little, K. E. Healy, and D. Schaffer, "Engineering biomaterials for synthetic neural stem cell microenvironments," Chemical Reviews, vol. 108, no. 5, pp. 1787-1796, 2008.

[128] K. A. Kyburz and K. S. Anseth, "Three-dimensional hMSC motility within peptide-functionalized PEG-based hydrogels of varying adhesivity and crosslinking density," Acta Biomaterialia, vol. 9, no. 5, pp. 6381-6392, 2013. 
[129] S. M. Willerth, A. Rader, and S. E. Sakiyama-Elbert, "The effect of controlled growth factor delivery on embryonic stem cell differentiation inside fibrin scaffolds," Stem Cell Research, vol. 1, no. 3, pp. 205-218, 2008.

[130] L. Macri, D. Silverstein, and R. A. F. Clark, "Growth factor binding to the pericellular matrix and its importance in tissue engineering," Advanced Drug Delivery Reviews, vol. 59, no. 13, pp. 1366-1381, 2007.

[131] A. Iwasaki and R. Medzhitov, "Regulation of adaptive immunity by the innate immune system," Science, vol. 327, no. 5963, pp. 291-295, 2010.

[132] C. R. Jenney and J. M. Anderson, "Adsorbed serum proteins responsible for surface dependent human macrophage behavior," Journal of Biomedical Materials Research, vol. 49, no. 4, pp. 435-447, 2000.

[133] A. I. Teixeira, J. K. Duckworth, and O. Hermanson, "Getting the right stuff: controlling neural stem cell state and fate in vivo and in vitro with biomaterials," Cell Research, vol. 17, no. 1, pp. 56-61, 2007.

[134] S. M. Willerth and S. E. Sakiyama-Elbert, "Approaches to neural tissue engineering using scaffolds for drug delivery," Advanced Drug Delivery Reviews, vol. 59, no. 4-5, pp. 325-338, 2007.

[135] S. P. Zustiak, Y. Wei, and J. B. Leach, "Protein-hydrogel interactions in tissue engineering: mechanisms and applications," Tissue Engineering B: Reviews, vol. 19, no. 2, pp. 160-171, 2013.

[136] S. Konagaya, K. Kato, T. Nakaji-Hirabayashi, and H. Iwata, "Selective and rapid expansion of human neural progenitor cells on substrates with terminally anchored growth factors," Biomaterials, vol. 34, no. 25, pp. 6008-6014, 2013.

[137] Y. Aizawa, N. Leipzig, T. Zahir, and M. Shoichet, “The effect of immobilized platelet derived growth factor AA on neural stem/progenitor cell differentiation on cell-adhesive hydrogels," Biomaterials, vol. 29, no. 35, pp. 4676-4683, 2008.

[138] D. S. W. Benoit and K. S. Anseth, "Heparin functionalized PEG gels that modulate protein adsorption for hMSC adhesion and differentiation," Acta Biomaterialia, vol. 1, no. 4, pp. 461-470, 2005.

[139] D. S. W. Benoit, A. R. Durney, and K. S. Anseth, "The effect of heparin-functionalized PEG hydrogels on three-dimensional human mesenchymal stem cell osteogenic differentiation," Biomaterials, vol. 28, no. 1, pp. 66-77, 2007.

[140] S. M. Willerth, T. E. Faxel, D. I. Gottlieb, and S. E. SakiyamaElbert, "The effects of soluble growth factors on embryonic stem cell differentiation inside of fibrin scaffolds," Stem Cells, vol. 25, no. 9, pp. 2235-2244, 2007.

[141] B. Ananthanarayanan, L. Little, D. V. Schaffer, K. E. Healy, and M. Tirrell, "Neural stem cell adhesion and proliferation on phospholipid bilayers functionalized with RGD peptides," Biomaterials, vol. 31, no. 33, pp. 8706-8715, 2010.

[142] Y.-J. Ren, H. Zhang, H. Huang et al., "In vitro behavior of neural stem cells in response to different chemical functional groups," Biomaterials, vol. 30, no. 6, pp. 1036-1044, 2009.

[143] E. Bible, D. Y. S. Chau, M. R. Alexander, J. Price, K. M. Shakesheff, and M. Modo, "The support of neural stem cells transplanted into stroke-induced brain cavities by PLGA particles," Biomaterials, vol. 30, no. 16, pp. 2985-2994, 2009.

[144] E. Bible, O. Qutachi, D. Y. S. Chau, M. R. Alexander, K. M. Shakesheff, and M. Modo, "Neo-vascularization of the stroke cavity by implantation of human neural stem cells on VEGFreleasing PLGA microparticles," Biomaterials, vol. 33, no. 30, pp. 7435-7446, 2012.
[145] A. J. Engler, S. Sen, H. L. Sweeney, and D. E. Discher, "Matrix elasticity directs stem cell lineage specification," Cell, vol. 126, no. 4, pp. 677-689, 2006.

[146] K. Saha, J. F. Pollock, D. V. Schaffer, and K. E. Healy, "Designing synthetic materials to control stem cell phenotype," Current Opinion in Chemical Biology, vol. 11, no. 4, pp. 381-387, 2007.

[147] B. Trappmann, J. E. Gautrot, J. T. Connelly et al., "Extracellularmatrix tethering regulates stem-cell fate," Nature Materials, vol. 11, pp. 642-649, 2012.

[148] B. S. Elkin, A. Ilankovan, and B. Morrison III, "Age-dependent regional mechanical properties of the rat hippocampus and cortex," Journal of Biomechanical Engineering, vol. 132, no. 1, Article ID 011010, 2010.

[149] M. Iwashita, N. Kataoka, K. Toida, and Y. Kosodo, "Systematic profiling of spatiotemporal tissue and cellular stiffness in the developing brain," Development, vol. 141, no. 19, pp. 3793-3798, 2014.

[150] Y. J. Li, E. H. Chung, R. T. Rodriguez, M. T. Firpo, and K. E. Healy, "Hydrogels as artificial matrices for human embryonic stem cell self-renewal," Journal of Biomedical Materials Research-Part A, vol. 79, no. 1, pp. 1-5, 2006.

[151] N. D. Leipzig and M. S. Shoichet, "The effect of substrate stiffness on adult neural stem cell behavior," Biomaterials, vol. 30, no. 36, pp. 6867-6878, 2009.

[152] K. Saha, A. J. Keung, E. F. Irwin et al., "Substrate modulus directs neural stem cell behavior," Biophysical Journal, vol. 95, no. 9, pp. 4426-4438, 2008.

[153] A. Banerjee, M. Arha, S. Choudhary et al., "The influence of hydrogel modulus on the proliferation and differentiation of encapsulated neural stem cells," Biomaterials, vol. 30, no. 27, pp. 4695-4699, 2009.

[154] A. I. Teixeira, S. Ilkhanizadeh, J. A. Wigenius, J. K. Duckworth, O. Inganäs, and O. Hermanson, "The promotion of neuronal maturation on soft substrates," Biomaterials, vol. 30, no. 27, pp. 4567-4572, 2009.

[155] R. McBeath, D. M. Pirone, C. M. Nelson, K. Bhadriraju, and C. S. Chen, "Cell shape, cytoskeletal tension, and RhoA regulate stem cell lineage commitment," Developmental Cell, vol. 6, no. 4, pp. 483-495, 2004.

[156] G. T. Christopherson, H. Song, and H.-Q. Mao, “The influence of fiber diameter of electrospun substrates on neural stem cell differentiation and proliferation," Biomaterials, vol. 30, no. 4, pp. 556-564, 2009.

[157] J. B. Recknor, D. S. Sakaguchi, and S. K. Mallapragada, "Directed growth and selective differentiation of neural progenitor cells on micropatterned polymer substrates," Biomaterials, vol. 27, no. 22, pp. 4098-4108, 2006. 

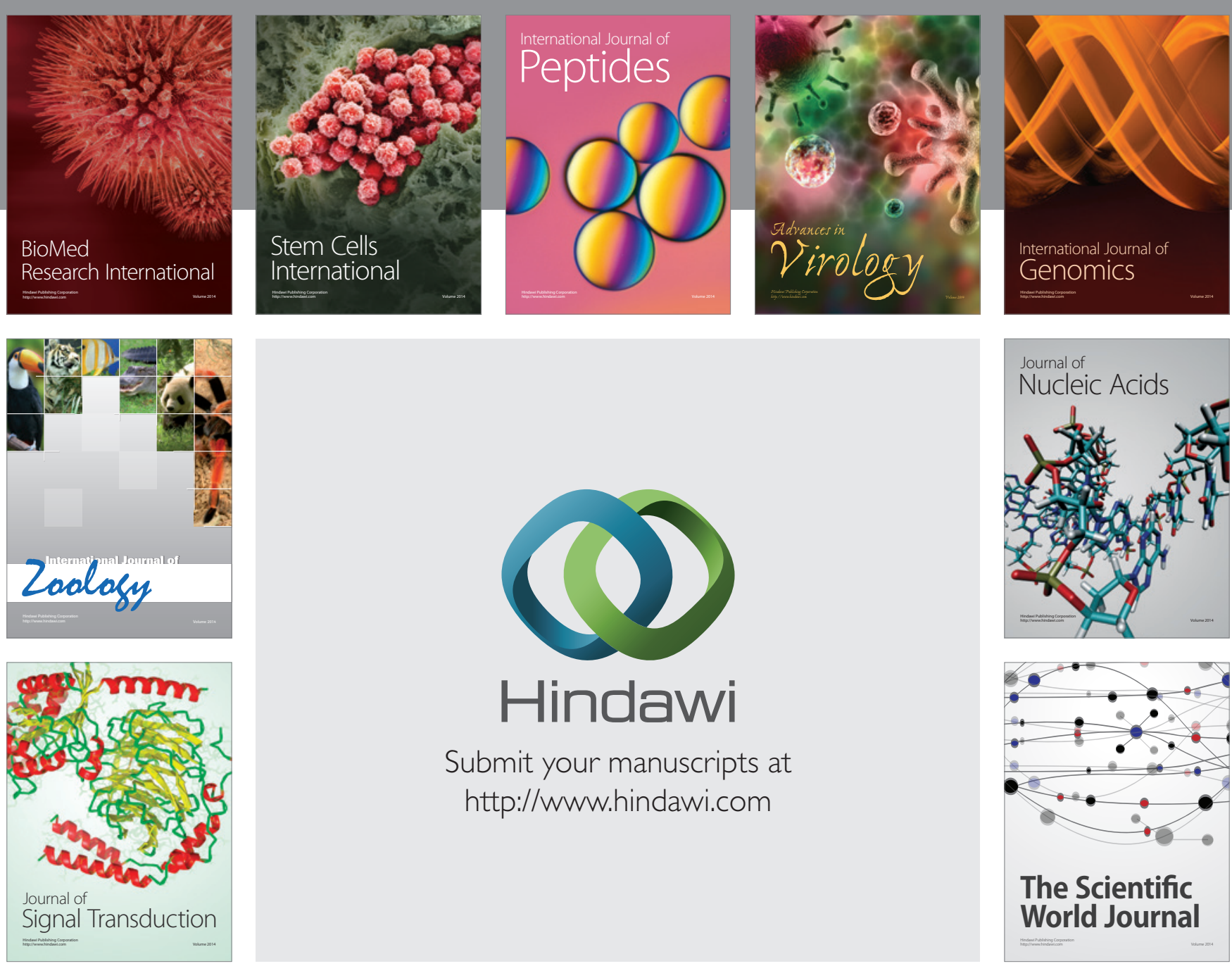

Submit your manuscripts at

http://www.hindawi.com
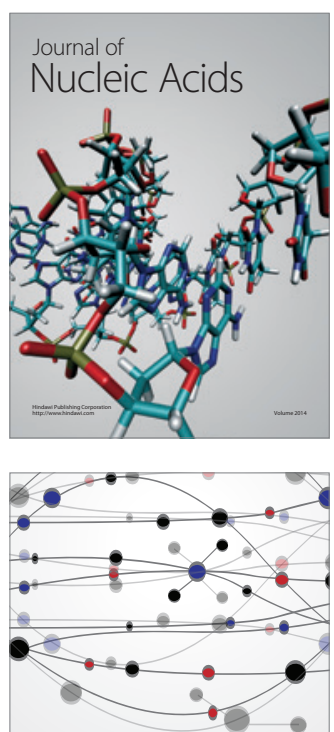

The Scientific World Journal
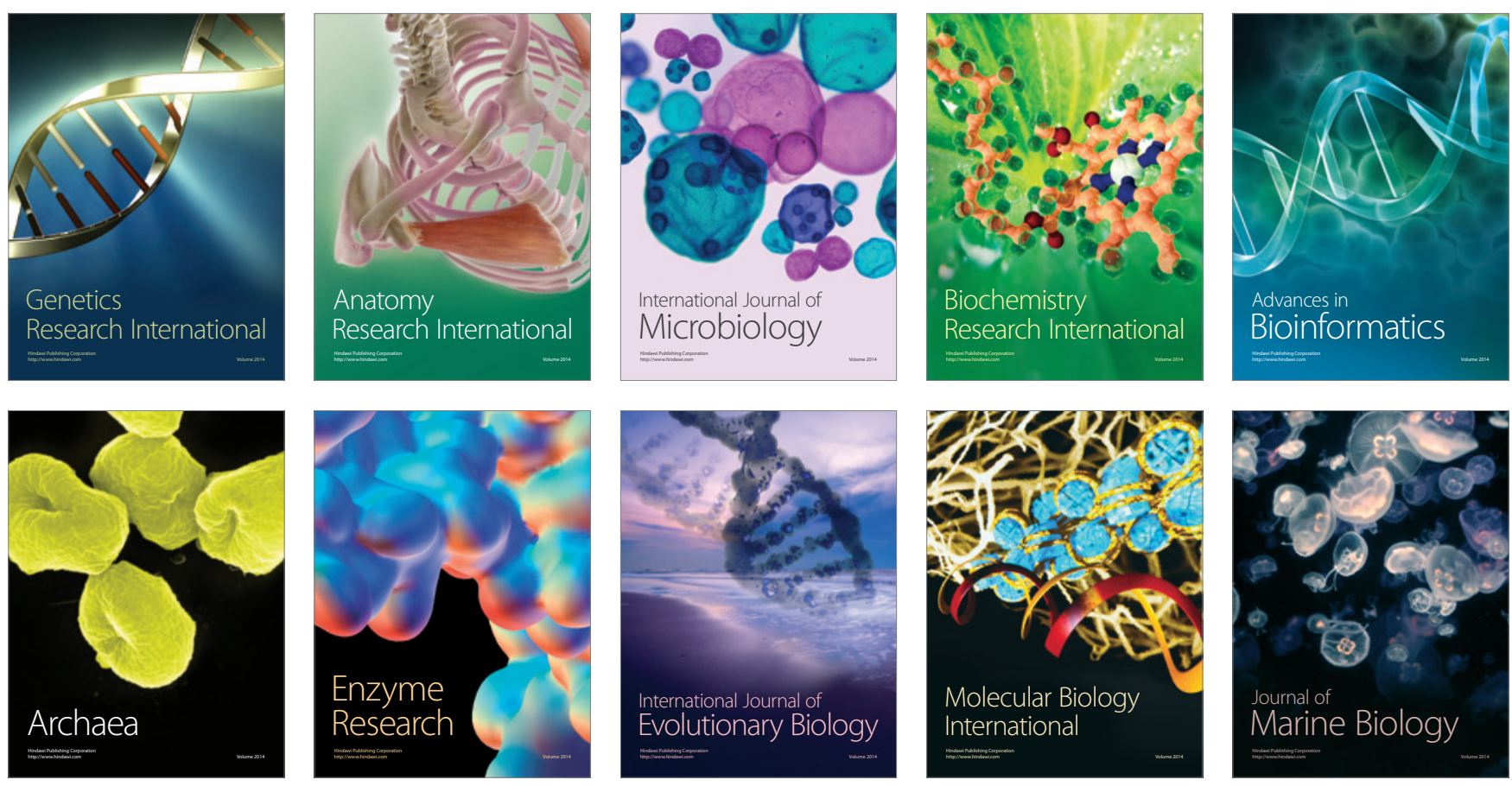